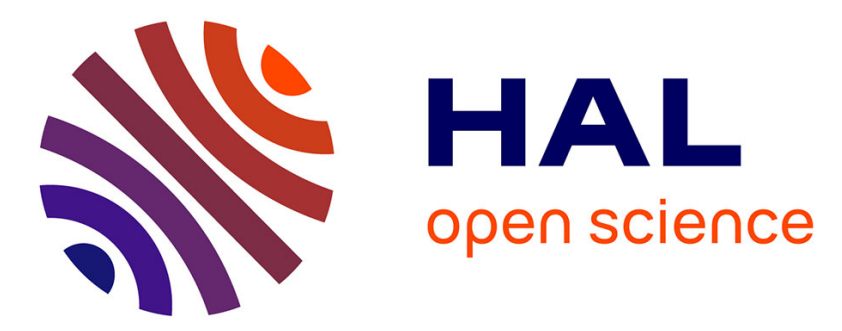

\title{
Clinical characteristics and predictive score of dengue vs. chikungunya virus infections
}

Timothée Bonifay, C Bonnefoy, D Blanchet, M. Dueymes, Mathieu Nacher, Félix Djossou, Loïc Epelboin

\section{- To cite this version:}

Timothée Bonifay, C Bonnefoy, D Blanchet, M. Dueymes, Mathieu Nacher, et al.. Clinical characteristics and predictive score of dengue vs. chikungunya virus infections. Médecine et Maladies Infectieuses, In press. hal-01845510

\author{
HAL Id: hal-01845510 \\ https://hal.science/hal-01845510
}

Submitted on 22 Oct 2021

HAL is a multi-disciplinary open access archive for the deposit and dissemination of scientific research documents, whether they are published or not. The documents may come from teaching and research institutions in France or abroad, or from public or private research centers.
L'archive ouverte pluridisciplinaire HAL, est destinée au dépôt et à la diffusion de documents scientifiques de niveau recherche, publiés ou non, émanant des établissements d'enseignement et de recherche français ou étrangers, des laboratoires publics ou privés.

\section{(ㅇ)(1) $\$$}

Distributed under a Creative Commons Attribution - NonCommercial| 4.0 International 


\section{Caractéristiques cliniques et score prédictif d'infection par le virus de la dengue versus chikungunya}

\section{Clinical characteristics and predictive score of dengue vs. chikungunya virus infections}

Timothée Bonifay*1,2 ${ }^{1,}$ Guillaume Vesin ${ }^{1}$, Bastien Bidaud ${ }^{1}$, Clémence Bonnefoy ${ }^{2,4}$, Maryvonne Dueymes ${ }^{5}$, Mathieu Nacher ${ }^{3,6}$, Félix Djossou ${ }^{1,6}$, and Loïc Epelboin ${ }^{1,6}$

1 Unité de maladie infectieuse et tropicale, Centre Hospitalier Andrée Rosemon, Cayenne F97300, Guyane française, France

2 Département de médecine générale, Université des Antilles, France

3 Centre d'Investigation Clinique Antilles Guyane, Inserm CIC 1424, Cayenne F-97300, Guyane française, France

4 Service d'accueil des urgences, Centre Hospitalier Andrée Rosemon, Cayenne F-97300, Guyane française, France

5 Laboratoire Hospitalier universitaire d'immunologie, Centre Hospitalier Andrée Rosemon, Cayenne F-97300, Guyane française, France

6 Equipe EA 3593, Ecosystèmes Amazoniens et Pathologie Tropicale, Université de Guyane, Cayenne F-97300, Guyane française, France

Keywords: chikungunya, dengue, French Guiana, arboviruses, predictive score Mots clés : chikungunya, dengue, Guyane française, arbovirus, score prédictif

\section{Corresponding author}

Timothée Bonifay, MD,

Unité de maladie infectieuse et tropicale, Centre hospitalier de Cayenne - Av des flamboyants, Cayenne 97306, Guyane française 
Email address: timothee.bonifay@gmail.com

Phone: +594594 395040 / Fax : +594594395041

\section{Alternate author}

Loïc Epelboin, MD

Unité de maladie infectieuse et tropicale, Centre hospitalier de Cayenne - Av des flamboyants, Cayenne 97306, Guyane française

Mail : epelboincrh@hotmail.fr

Phone : +594594395040 / Fax : +594594395041 


\section{ABSTRACT}

Background. Chikungunya (CHIKV) and dengue viruses (DENV) are two arboviruses with epidemic potential and similar clinical presentations. The potential life-threatening risk associated with DENV justifies an immediate biological assessment and medical follow-up which may be delayed for CHIKV.

Objectives. To compare the clinical variables that would help differentiate patients infected with CHIKV or DENV, and then to compute a predictive score.

Patients and method. Retrospective case-control study comparing CHIKV-infected patients diagnosed by RT-PCR in 2014 with patients infected with DENV diagnosed by positive NS1 antigen test in 2013. Children aged $<15$ years and pregnant women were excluded. Clinical and biological variables were compared, and a multivariate analysis was performed. A clinical score was developed using the $\beta$ coefficients to differentiate the infections.

Results. Over the study period 168 patients infected with CHIKV were compared with 452 patients with DENV. The clinical variables independently associated with CHIKV was joint and back pain, and those associated with DENV were headache, muscle pain, nausea/vomiting, diarrhea, and hemorrhagic signs. The clinical score had $98 \%$ sensitivity for DENV and a ROC curve of 0.96.

Conclusion. These two infections have a similar clinical presentation but the use of the proposed clinical score during the acute phase of the disease would make it possible to identify cases of DENV during a CHIKV epidemic to suggest adequate patient management. 


\section{RÉSUMÉ}

Objectifs. Les virus du chikungunya (CHIKV) et de la dengue (DENV) sont deux arbovirus à fort potentiel épidémique avec une présentation clinique similaire. Le risque potentiellement mortel associé à DENV justifie une évaluation biologique immédiate et un suivi médical, qui peuvent être retardés en cas d'infection par CHIKV. L'objectif de l'étude était de comparer les variables cliniques qui permettraient de différencier un patient infecté par le CHIKV ou le DENV puis de réaliser un score prédictif.

Patients et méthode. Étude cas-témoins rétrospective comparant des patients infectés par CHIKV diagnostiqués par RT-PCR en 2014 à des patients infectés par DENV diagnostiqués par antigène NS1 positif en 2013. Les enfants < 15 ans et les femmes enceintes ont été exclus. Les variables cliniques et biologiques ont été comparées et une analyse multivariée a été réalisée. Un score clinique a été construit à partir des coefficients $\beta$ pour différencier les deux infections.

Résultats. 168 patients infectés par CHIKV ont été comparés à 452 patients atteints par DENV. Les variables cliniques associées à CHIKV étaient la présence d'arthralgies et rachialgies, et celles associées au DENV étaient céphalées, myalgies, nausées/vomissements, diarrhées et signes hémorragiques. Le score clinique avait une sensibilité de $98 \%$ pour le DENV et une courbe ROC de 0,96.

Conclusions. Ces deux infections ont une présentation clinique similaire mais l'utilisation du score clinique proposé durant la phase aiguë de la maladie permettrait d'identifier les cas de DENV lors d'une épidémie de CHIKV pour proposer une prise en charge adéquate. 


\section{Background}

French Guiana is a French overseas territory located on the Northeastern coast of South America. Because of its geographical location, it is exposed to tropical diseases while benefiting from health facilities with European standards. Chikungunya virus (CHIKV) and dengue fever virus (DENV) are two arboviruses with high epidemic potential. Both of these viruses have been circulating in French Guiana since 2014. The four serotypes of DENV circulate in an endemic-epidemic form and the last 2012-2013 outbreak affected nearly 6\% of the population. The first local transmission of CHIKV was identified in December 2013. CHIKV re-emerged and caused a large epidemic that affected almost all countries of America and infected nearly 1.7 million of individuals over two years [1-4]. In French Guiana CHIKV only affected 6-7\% of the population (versus 34\% in Martinique for instance) [5]. The distribution of both viruses is similar because of their common vectors, mainly Aedes aegypti and Aedes albopictus [6]. Ae. aegypti mosquitoes have so far been the sole vectors implicated in these outbreaks and Ae. albopictus have not been reported in French Guiana [6]. These two arboviruses are characterized by a so-called nonspecific "dengue-like syndrome" (fever, headache, and muscle pain) making clinical differential diagnosis of CHIKV and DENV difficult [7].

The hemorrhagic risk and the severe presentations associated with DENV justifies an immediate biological assessment and a clinical follow-up, even in the absence of clinical warning signs. However, the biological assessment and clinical follow-up may be postponed for CHIKV, particularly in the context of a CHIKV outbreak in an endemic area for DENV.

\section{Objectives}


The main objective of the study was to compare the epidemiological, clinical, and biological characteristics which would help differentiate patients infected with CHIKV or DENV at the first medical consultation. The secondary objective was to compute a predictive score to differentiate DENV from CHIKV infection.

\section{Study design}

A monocenter retrospective case-control study was conducted to compare a group of patients infected with CHIKV with a group infected with DENV. This study was performed in the hospital of Cayenne, the main city and the main hospital in French Guiana.

\section{Inclusion criteria of participants presenting with chikungunya fever}

Retrospectively, all patients diagnosed and/or treated at the hospital for chikungunya from April to June 2014 (i.e., the first months of the outbreak) constituted our case group. A case of CHIKV infection was defined as a clinical presentation suggestive of an arbovirus infection [8] and a microbiological diagnosis of acute CHIKV infection diagnosed by RT-PCR. All patients underwent medical consultation at the hospital, in the emergency department or infectious diseases department, with an initial standard infectious biological assessment including CHIKV RT-PCR, DENV diagnostic test (NS1 antigen and IgM), thin and thick blood smear for malaria, and standard blood tests at the physician's discretion. Nucleic acid was extracted from serum using a MagNA Pure LC total nucleic acid isolation kit and a MagNA Pure LC2.0 instrument (Roche). Real time RT-PCR amplification was performed with the RealStar ${ }^{\circledR}$ Chikungunya RT-PCR kit 1.0 (CE-IVD marking) (Altona Diagnostics) and a thermocycler 7500 Applied Biosystem. Qualitative detection of dengue virus NS1 antigen was performed in serum by enzyme immunoassay with Platelia ${ }^{\mathrm{TM}}$ dengue NS1 Ag kit (Biorad). All biological tests were performed at the hospital laboratory. 


\section{Inclusion criteria of participants presenting with dengue fever}

A retrospective collection was then performed to create a control group of patients presenting with acute DENV infection. The group was exhaustively made of patients presenting with a compatible clinical picture of arbovirus infection [8] and a positive NS1 antigen test at the Cayenne hospital laboratory from March to August 2013 during a DENV outbreak (mainly DENV2). The NS1 test has been historically used at the hospital and we could not perform the DENV PCR.

\section{Exclusion criteria}

The exclusion criteria were age under 15 years, ongoing pregnancy, and/or incomplete medical records. Children and pregnant women were monitored in the departments of pediatrics and gynecology-obstetrics respectively, and thus did not allow for a uniform data collection.

\section{Data collection and statistical methods}

The epidemiological, clinical, and biological data was collected from computerized medical records: the emergency medical record $\left(\right.$ DMUnet $\left.^{\circledR}\right)$, the common medical record $\left(\right.$ Cora $\left.^{\circledR}\right)$, and the biological medical software $\left(\mathrm{SRI}^{\circledR}\right)$. A clinical variable not reported in the chart was considered negative. The first day of fever was defined as the first day of the disease.

The clinical and biological characteristics of the groups were compared at the first consultation using a chi-square test, Student's $t$ test for the normally distributed quantitative variables, or the non-parametric Mann-Whitney test for the other continuous variables. Variables were considered significant with $p<0.05$. 
Unconditional multiple logistic regression was used to compute a predictive score with high sensitivity for identifying probable DENV versus CHIKV infection. The most relevant clinical variables with a significance level of less than 0.2 were selected and included in the multivariate model. Nonspecific or inconsistently reported variables in initial medical charts were considered unreliable and were excluded. A step-by-step backward elimination procedure was used starting with variables with the highest $p$ value. The predictive score was computed using the $\beta$-coefficients resulting from the multivariate analysis. We used 3,500 bootstrapped replications to obtain robust estimates. We then evaluated the value of our model by estimating the area under the ROC (receiver operating characteristic) curve and by calculating the sensitivity and specificity scores of each result to evaluate the performance of the test. We also computed a goodness of fit test to compare the observed sample distribution. The data was anonymously collected on Microsoft Access $2010^{\circledR}$ and analyzed on Stata $12.0^{\circledR}$

\section{Ethical consideration}

The present monocenter study included anonymized patient records (the database did not include names or any variable that could lead to the identification of patients) as authorized by the French regulatory authorities. The database was declared to the French Data Protection Authority (French acronym CNIL) (no. TFN1490159N) as per French legal requirements. 


\section{Results}

A total of 620 patients were selected for the study: 168 patients for the CHIKV group and 452 patients for the DENV group (Figure 1). No CHIKV-DENV co-infection was identified during the CHIKV epidemic nor was co-infection with malaria identified. The male-to-female sex ratio was equal in both groups at $\sim 1 / 1$. The study population was significantly older in the CHIKV group and had more comorbid conditions. The time between symptom onset and the first consultation was shorter in the CHIKV group. At the end of this consultation $8.3 \%$ of CHIKV patients were hospitalized versus $35.2 \%$ of patients in the DENV group $(p<0.001)$.

The significant variables associated with CHIKV were joint and back pains and those associated with DENV were diarrhea, abdominal pain, and neurological signs (Table 1). No CHIKV patient had severe hemorrhagic presentations, only $1.2 \%$ had minor hemorrhage (epistaxis or gingival hemorrhage) versus $15.9 \%$ for the DENV group (OR 0.06 [0.01-0.25] $p<0.001)$. Of the 14 hospitalized CHIKV patients, four were considered as having an atypical or severe presentation (two had uncontrolled pain and two had concomitant pancreatitis or cholecystitis). Nine DENV patients were classified group C (severe dengue): three for severe plasma leakage, three for severe bleeding (spleen rupture, psoas hematoma, and extensive purpura), and three for severe organ impairment. DENV patients had a more frequent rash at the time of their first consultation but the CHIKV group had more frequent pruritus in particular without rash (OR $7.5[3.1-20.0] p<0.001)$. More than $25 \%$ of skin presentations observed in patients of the DENV group occurred after the first consultation versus $4.2 \%$ for CHIKV patients.

CHIKV was significantly associated with CRP $>30 \mathrm{mg} / \mathrm{l}$. The variables most often associated with DENV were thrombocytopenia $<150 \mathrm{G} / \mathrm{l}$, neutropenia $<1,500 / \mathrm{mm}^{3}$, lymphopenia 
$<500 / \mathrm{mm}^{3}$, and transaminase level twice higher than the normal value (Table 2). In the DENV group $35.9 \%$ of patients with hemorrhagic signs had a platelet count $<100 \mathrm{G} / 1$ versus $13.4 \%$ of patients in the CHIKV group (OR $3.62[2.14-6.1] p<0.001)$.

Eleven clinical variables were included in the multivariate model: headache, joint pain, muscle pain, back pains, abdominal pain, nausea and/or vomiting, food intolerance (repeated vomiting), diarrhea, cutaneous signs without pruritus, hemorrhagic signs, and neurological signs. The variables independently associated with CHIKV in the multivariate analysis were joint and back pains, and those associated with DENV were headache, muscle pain, nausea/vomiting, diarrhea, and hemorrhagic signs (Table 3). Positive $\beta$ coefficients were in favor of CHIKV infection and negative coefficients in favor of DENV infection. Records with at least one missing value were removed from the model. Tested on our groups, the ROC curve showed an area under the curve (AUC) of 0.96. The correlation coefficient between CHIKV and DENV was 70.71 ( $p=0.65$; Pearson's goodness of fit). The predictive score was tested using the demonstrated diagnosis of each patient to obtain a sensitivity and specificity of different score values (Figure 2). The cut-off allowing the interpretation of results was chosen according to our initial objectives: the most interesting cut-off was a very high sensitivity for DENV, in order to avoid missing a case of DENV during an ongoing outbreak of CHIKV as DENV could be more severe. The chosen cut-off was 2 . A score $\leq 2$ had a sensitivity of $98 \%$ for DENV and a specificity of $63 \%$, with a false negative number of 11 in 452 DENV patients tested $(2.4 \%)$. 


\section{Discussion}

Over a four-year period, Latin America and French Guiana in particular, have faced three successive epidemics of different arboviruses (DENV 2012-2013, CHIKV 2014-2015, and Zika virus [ZIKV] 2015-2016), not to mention the yellow fever virus in Brazil in 2017. Two of these viruses had never been recorded on the continent for at least one century, i.e. CHIKV and ZIKV [9]. Over the past 10 years an increase in the number of DENV outbreaks has also been observed, with more cases and more severe cases [8]. New risks include the creation of an endemic CHIKV cycle [10], new epidemics of CHIKV via an ECSA (East, Central and South African lineage) or IOL (Indian Ocean lineage) genotype, the spread of Ae. albopictus in the territory, or the emergence of new arboviruses [11]. A mutation of CHIKV, making transmission by Ae. albopictus possible, occurred independently on at least four separate occasions on Reunion Island (2004/2005) and India (2008) for the IOL (Indian Ocean lineage), and in Cameroon (2006) and Gabon (2007) for the Central African lineage (ECSA) [12]. There is growing evidence that, during the last IOL and ECSA outbreaks, this latter mosquito seemed to transmit CHIKV more efficiently than Ae. aegypti [11-13]. This is particularly important as Ae. albopictus occurs in more temperate areas and the risk of CHIKV and DENV outbreaks emerging in Western Europe is increasing every year $[14,15]$.

The present study is the largest ever performed comparing clinical features of CHIKV and DENV infections. We identified seven published studies comparing CHIKV and DENV [7,16-21]. Most studies included less than 50 patients; results were therefore not very informative. The only two studies with large samples reported very different results. A 2010 study performed in Gabon concluded that the two infections were clinically indistinguishable, unlike the conclusion of a 2008 study performed in Singapore $[7,18]$.

Patients who consulted during the CHIKV epidemic were on average 10 years older than 
DENV patients, as already mentioned in other studies $[16,18,21]$. Dengue fever is endemic in French Guiana. As immunity increases with age, the virus targets a younger and less immune population [22]. Several studies reported a lower sensitivity rate with NS1 test in acute secondary dengue than in acute primary dengue. The NS1 test is therefore more likely to diagnose acute primary dengue and select a younger population [23]. On the contrary, during the CHIKV epidemic the population was not previously immunized, and people of the extreme ages were naturally more affected. Patients consulted earlier during the CHIKV epidemic than the DENV epidemic because of greater concern, severe symptoms, a source of epidemic near the hospital, and pressure of health authorities and the media. At the beginning of the epidemic, CHIKV was assumed to be more serious than DENV in the public imagination [24]. The vision of saturated hospitals and chronic presentations strongly encouraged patients to consult earlier, at least at the beginning of the epidemic. It should also be noted that the outbreak started close to the hospital (unpublished data) and that emergency departments were the primary access to care for many patients. Its proximity thus made it easier for patients to consult.

The choice of the cut-off made it possible to obtain a very sensitive clinical score to differentiate DENV from CHIKV. A score between -9 and +2 was in favor of DENV and between +3 and +6 in favor of CHIKV. The presence of arthritis was indicative of CHIKV infection (Table 4). The use of the score requires two prerequisites: an epidemic context with a circulation of both viruses and patients with dengue-like syndrome. Detection of dengue cases is essential in endemic areas. Several scores have been published. For instance one has been built to differentiate dengue from other febrile illnesses [25]. Most clinical symptoms are based on hemorrhagic signs which are not always observed, e.g. only $26.3 \%$ of our DENV patients presented with clinical symptoms during the consultation. Our score used nonspecific 
signs which were not associated with the physician's experience or with subjective judgement. Considering the potentially severe complications of DENV - less frequently observed with CHIKV -, the score model was built to obtain a very high sensitivity to DENV, at the expense of its specificity. Differentiating DENV in the context of a CHIKV epidemic will allow for the better management of patients and will help decide on criteria for monitoring, hospitalization, and/or blood tests. The need for a systematic biological check-up in patients presenting with CHIKV infection can be questioned considering the cost and low benefit provided by the medical care. On the other hand, DENV involves clinical and biological monitoring and a particularly careful search for warning signs [26]. However, this score should be externally validated in other sites to ensure its robustness.

Due to the retrospective nature of the study, the exhaustiveness of the clinical picture and anamnesis was variable. To limit biases, files with missing data were not included and unreliable variables were not used in the diagnostic score, such as asthenia, anorexia, or retroorbital pain, as they mainly depend on the physician's judgement in retrospective analyses. The CHIKV study was performed at the beginning of the epidemic, at a time when the epidemic was predominantly affecting the Cayenne area. Patients were frightened by this new virus and were mainly seen at the emergency department [24]. We were not able to assess prior dengue exposure because $(i)$ anti-DENV IgG tests were not performed in our study, (ii) the question regarding previous DENV infections was asked to patients, but anamnesis alone is not very reliable because of potential differential diagnoses. Patients are usually selected in studies using dengue PCR [27] but since 2006 the Cayenne hospital uses a rapid diagnostic test to diagnose dengue. The sensitivity of that test has been demonstrated on several occasions on a regional and international scale [28-31]. 
These two infections have a similar clinical presentation but the use of the proposed clinical score during the acute phase of the disease would make it possible to identify cases of DENV during a CHIKV outbreak to implement adequate patient management. The study, despite its limitations, has large samples and provides consistent results. Another outbreak would allow for an external validation to consolidate the use of the score. 


\section{Acknowledgments}

The authors would like to thank the physicians who supported the patients and helped collect clinical data and fill in the forms: Philippe Abboud, Gaëlle Walter, Aba Mahamat, Yasmina Briquet, Rémi Mutricy, and Elodie Rossigneux. They would also like to thank the biologists who performed the RT-PCR: Denis Blanchet and Magalie Pierre-Demar.

\section{Contribution of authors}

T.B. designed the study, performed the literature analysis, performed data acquisition and analysis, interpreted the data, wrote the first draft of the article and tables.

G.V. performed data acquisition.

B.B. performed data acquisition.

C.B. performed data acquisition and reviewed the article.

M.D. reviewed the article.

F.D. reviewed the article.

M.N. reviewed the article, translated the article, and interpreted the results.

L.E. designed the study project, performed the data analysis, interpreted the results, and reviewed the article. 


\section{REFERENCES}

1. Kuno G. A Re-Examination of the History of Etiologic Confusion between Dengue and Chikungunya. PLoS Negl. Trop. Dis. 2015 12;9:e0004101. doi: 10.1371/journal.pntd.0004101

2. Halstead SB. Reappearance of Chikungunya, Formerly Called Dengue, in the Americas. Emerg. Infect. Dis. 2015;21:557-61. doi: 10.3201/eid2104.141723

3. Geographic Distribution | Chikungunya virus | CDC [Internet]. [cited 2017 16];doi: https://www.cdc.gov/chikungunya/geo/

4. Weaver SC, Lecuit M. Chikungunya Virus and the Global Spread of a Mosquito-Borne Disease. N. Engl. J. Med. 2015 26;372:1231-9. doi: 10.1056/NEJMra1406035

5. InVS. Surveillance du chikungunya - Bulletin bimestriel : Période du 13 juin au 4 septembre 2016 - Guyane. ARS; 2016.

6. Vega-Rúa A, Lourenço-de-Oliveira R, Mousson L, Vazeille M, Fuchs S, Yébakima A, et al. Chikungunya Virus Transmission Potential by Local Aedes Mosquitoes in the Americas and Europe. PLoS Negl. Trop. Dis. 2015 20;9:e0003780. doi: 10.1371/journal.pntd.0003780

7. Nkoghe D, Kassa Kassa RF, Bisvigou U, Caron M, Grard G, Leroy EM. No clinical or biological difference between Chikungunya and Dengue Fever during the 2010 Gabonese outbreak. Infect. Dis. Rep. 2012 3;4:5. doi: 10.4081/idr.2012.e5

8. Simmons CP, Farrar JJ, van Vinh Chau N, Wills B. Dengue. N. Engl. J. Med. 2012;366:1423-1432.

9. Carey DE. Chikungunya and dengue: a case of mistaken identity? J. Hist. Med. Allied Sci. 1971;26:243-262.

10. Lourenço-de-Oliveira R, Failloux A-B. High risk for chikungunya virus to initiate an enzootic sylvatic cycle in the tropical Americas. PLoS Negl. Trop. Dis. 2017 29;11:e0005698. doi: 10.1371/journal.pntd.0005698

11. Vega-Rúa A, Zouache K, Girod R, Failloux A-B, Lourenço-de-Oliveira R. High Level of Vector Competence of Aedes aegypti and Aedes albopictus from Ten American Countries as a Crucial Factor in the Spread of Chikungunya Virus. J. Virol. 2014;88:6294-306. doi: 10.1128/JVI.0037014

12. Vazeille M, Zouache K, Vega-Rúa A, Thiberge J-M, Caro V, Yébakima A, et al. Importance of mosquito "quasispecies" in selecting an epidemic arthropod-borne virus. Sci. Rep. [Internet] 2016 7;6. doi: http://www.ncbi.nlm.nih.gov/pmc/articles/PMC4935986/doi: 10.1038/srep29564

13. Vazeille M, Mousson L, Martin E, Failloux A-B. Orally Co-Infected Aedes albopictus from La Reunion Island, Indian Ocean, Can Deliver Both Dengue and Chikungunya Infectious Viral Particles in Their Saliva. PLoS Negl. Trop. Dis. 2010 8;4:e706. doi: 10.1371/journal.pntd.0000706 
14. Kraemer MU, Sinka ME, Duda KA, Mylne AQ, Shearer FM, Barker CM, et al. The global distribution of the arbovirus vectors Aedes aegypti and Ae. albopictus. elife 2015 30;4:e08347. doi: 10.7554/eLife.08347

15. WHO | Chikungunya - Italy [Internet]. WHO [cited 2017 9];doi:

http://www.who.int/csr/don/15-september-2017-chikungunya-italy/en/

16. Kularatne S a. M, Gihan MC, Weerasinghe SC, Gunasena S. Concurrent outbreaks of Chikungunya and Dengue fever in Kandy, Sri Lanka, 2006-07: a comparative analysis of clinical and laboratory features. Postgrad. Med. J. 2009;85:342-6. doi: 10.1136/pgmj.2007.066746

17. Velasco JM, Valderama MT, Lopez MN, Chua D, Latog R, Roque V, et al. Chikungunya Virus Infections Among Patients with Dengue-Like Illness at a Tertiary Care Hospital in the Philippines, 2012-2013. Am. J. Trop. Med. Hyg. 2015 9;93:1318-24. doi: 10.4269/ajtmh.15-0332

18. Lee VJ, Chow A, Zheng X, Carrasco LR, Cook AR, Lye DC, et al. Simple Clinical and Laboratory Predictors of Chikungunya versus Dengue Infections in Adults. PLoS Negl. Trop. Dis. [Internet] 201227 [cited 2016 19];6. doi: http://www.ncbi.nlm.nih.gov/pmc/articles/PMC3459852/doi: 10.1371/journal.pntd.0001786

19. Sahadeo N, Mohammed H, Allicock OM, Auguste AJ, Widen SG, Badal K, et al. Molecular Characterisation of Chikungunya Virus Infections in Trinidad and Comparison of Clinical and Laboratory Features with Dengue and Other Acute Febrile Cases. PLoS Negl. Trop. Dis. [Internet] 201518 [cited 2016 28];9. doi: http://www.ncbi.nlm.nih.gov/pmc/articles/PMC4651505/doi: 10.1371/journal.pntd.0004199

20. Hochedez P, Canestri A, Guihot A, Brichler S, Bricaire F, Caumes E. Management of Travelers with Fever and Exanthema, Notably Dengue and Chikungunya Infections. Am. J. Trop. Med. Hyg. 2008 5;78:710-3.

21. Mohd Zim MA, Sam I-C, Omar SFS, Chan YF, AbuBakar S, Kamarulzaman A. Chikungunya infection in Malaysia: Comparison with dengue infection in adults and predictors of persistent arthralgia. J. Clin. Virol. 2013;56:141-5. doi: 10.1016/j.jcv.2012.10.019

22. Dhar-Chowdhury P, Paul KK, Haque CE, Hossain S, Lindsay LR, Dibernardo A, et al. Dengue seroprevalence, seroconversion and risk factors in Dhaka, Bangladesh. PLoS Negl. Trop. Dis. 2017 23;11:e0005475. doi: 10.1371/journal.pntd.0005475

23. Kumarasamy V, Chua SK, Hassan Z, Wahab AHA, Chem YK, Mohamad M, et al. Evaluating the sensitivity of a commercial dengue NS1 antigen-capture ELISA for early diagnosis of acute dengue virus infection. Singapore Med. J. 2007;48:669-73.

24. Fritzell C, Raude J, Adde A, Dusfour I, Quenel P, Flamand C. Knowledge, Attitude and Practices of Vector-Borne Disease Prevention during the Emergence of a New Arbovirus: Implications for the Control of Chikungunya Virus in French Guiana. PLOS Negl Trop Dis 2016 1;10:e0005081. doi: 10.1371/journal.pntd.0005081

25. Fernández E, Smieja $M$, Walter SD, Loeb M. A predictive model to differentiate dengue from other febrile illness. BMC Infect. Dis. [Internet] 2016 [cited 2018 27];16. doi: http://bmcinfectdis.biomedcentral.com/articles/10.1186/s12879-016-2024-ydoi: 10.1186/s12879-016-2024-y 
26. Special Programme for Research and Training in Tropical Diseases, World Health Organization, editors. Dengue: guidelines for diagnosis, treatment, prevention, and control. New ed. Geneva: TDR : World Health Organization; 2009.

27. Barkham TM, Chung YK, Tang KF, Ooi EE. The performance of RT-PCR compared with a rapid serological assay for acute dengue fever in a diagnostic laboratory. Trans. R. Soc. Trop. Med. Hyg. 2006;100:142-8. doi: 10.1016/j.trstmh.2005.05.015

28. Dussart P, Labeau B, Lagathu G, Louis P, Nunes MRT, Rodrigues SG, et al. Evaluation of an Enzyme Immunoassay for Detection of Dengue Virus NS1 Antigen in Human Serum. Clin. Vaccine Immunol. 2006;13:1185-9. doi: 10.1128/CVI.00229-06

29. Epelboin L, Boullé C, Ouar-Epelboin S, Hanf M, Dussart P, Djossou F, et al. Discriminating Malaria from Dengue Fever in Endemic Areas: Clinical and Biological Criteria, Prognostic Score and Utility of the C-Reactive Protein: A Retrospective Matched-Pair Study in French Guiana. PLOS NegI Trop Dis 2013 12;7:e2420. doi: 10.1371/journal.pntd.0002420

30. Ahmed NH, Broor S. Comparison of NS1 antigen detection ELISA, real time RT-PCR and virus isolation for rapid diagnosis of dengue infection in acute phase. J. Vector Borne Dis.

2014;51:194.

31. Anand AM, Sistla S, Dhodapkar R, Hamide A, Biswal N, Srinivasan B. Evaluation of NS1 Antigen Detection for Early Diagnosis of Dengue in a Tertiary Hospital in Southern India. J. Clin. Diagn. Res. JCDR 2016;10:DC01-4. doi: 10.7860/JCDR/2016/15758.7562 
Figure 1. Flow chart of the study

Figure 1. Diagramme de flux de l'étude

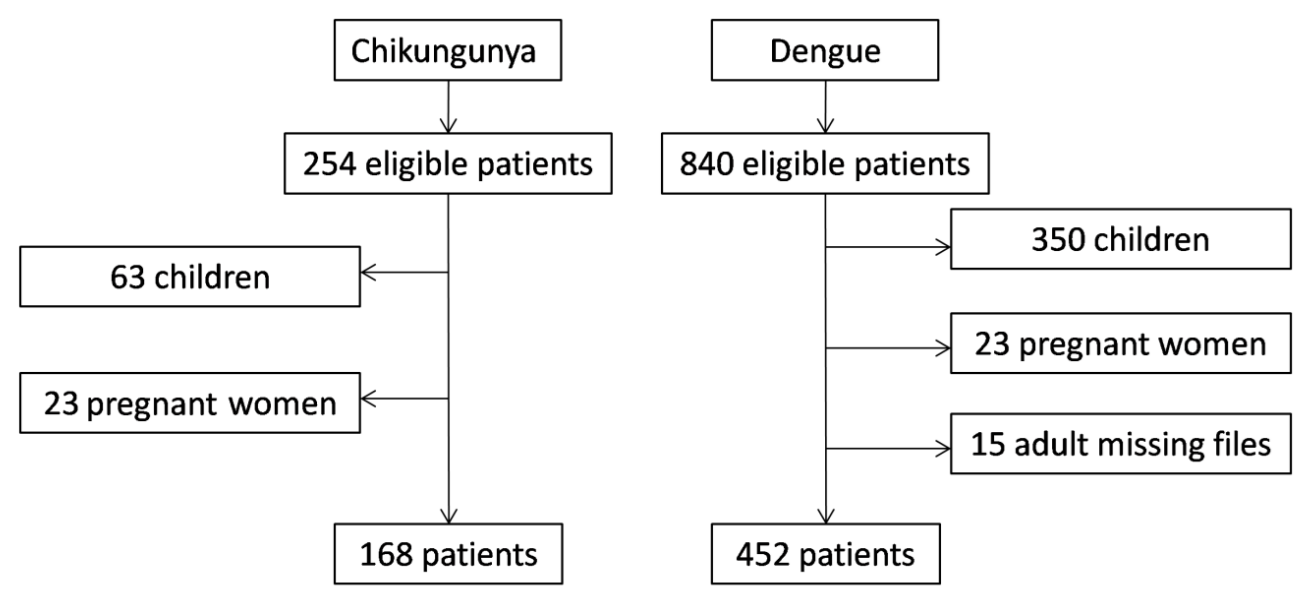


Figure 2. Sensitivity and specificity curves for the diagnosis of dengue based on the values obtained from the clinical predictive score for CHIKV vs. DENV. The figure indicates the calculated values and the $95 \%$ confidence intervals.

Figure 2. Courbes de sensibilité et spécificité en fonction des résultats possibles du score clinique prédictif d'une infection par DENV versus CHIKV. La figure indique les valeurs calculées ainsi que les intervalles de confiance.

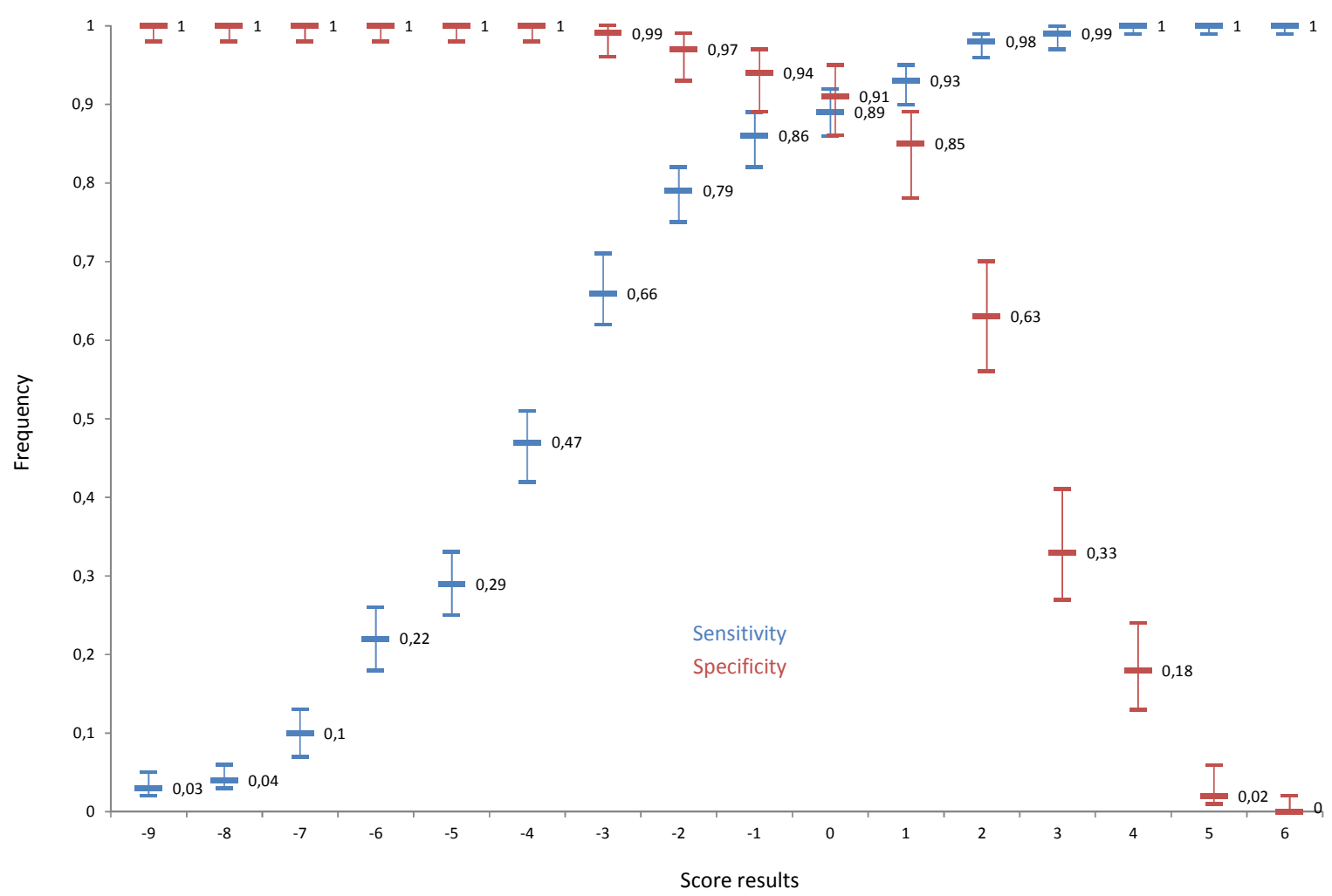


Table 1. Comparison of the demographical and clinical variables in the univariate analysis between CHIKV and DENV groups

Tableau 1. Comparaison en analyse univariée des variables démographiques et cliniques entre les groupes CHIKV et DENV

\begin{tabular}{|c|c|c|c|c|}
\hline Variables & $\begin{array}{c}\text { CHIKV } \\
\text { n=168 }(\%)\end{array}$ & $\begin{array}{c}\text { DENV } \\
\mathrm{n}=452(\%)\end{array}$ & OR $(95 \% \mathrm{CI})$ & $p$ \\
\hline Male sex & $77(45.8)$ & $226(50.0)$ & $0.85(0.58-1.23)$ & 0.36 \\
\hline Age $\geq 65$ years & $24(14.3)$ & $16(3.54)$ & $4.54(2.24-9.39)$ & $<0.001$ \\
\hline Age $<18$ years & $6(3.5)$ & $72(15.9)$ & $0.19(0.07-0.46)$ & $<0.001$ \\
\hline Comorbidity & $93(55.3)$ & $108(23.9)$ & $3.95(2.67-5.85)$ & $<0.001$ \\
\hline Hospitalized patients & $14(8.3)$ & $159(35.2)$ & $0.16(0.08-0.30)$ & $<0.001$ \\
\hline Consultation before day 3 & $85(50.1)$ & $163(36.1)$ & $1.82(1.25-2.64)$ & 0.01 \\
\hline Fever & $118 / 151(78.2)$ & $314 / 444(70.7)$ & $1.48(0.94-2.37)$ & 0.08 \\
\hline Headache & $97(57.7)$ & $371(82.1)$ & $0.30(0.20-0.45)$ & $<0.001$ \\
\hline Retro-orbital pain & $24(14.3)$ & $99(21.9)$ & $0.59(0.35-0.98)$ & 0.03 \\
\hline Joint pain & $156(92.9)$ & $74(16.4)$ & $66.4(34.4-136.8)$ & $<0.001$ \\
\hline Arthritis & $16(9.5)$ & $0(0.0)$ & - & - \\
\hline Muscle pain & $111(66.1)$ & $366(80.9)$ & $0.39(0.46-0.70)$ & $<0.001$ \\
\hline Back pain & $80(47.6)$ & $103(22.8)$ & $3.08(2.08-4.55)$ & $<0.001$ \\
\hline Cough & $14(8.3)$ & $63(13.9)$ & $0.56(0.28-1.05)$ & 0.06 \\
\hline Abdominal pain & $20(11.9)$ & $154(34.1)$ & $0.26(0.15-0.44)$ & $<0.001$ \\
\hline Nausea and/or vomiting & $43(25.6)$ & $253(60.0)$ & $0.27(0.18-0.41)$ & $<0.001$ \\
\hline Food intolerance* & $12(7.1)$ & $72(15.9)$ & $0.41(0.19-0.78)$ & 0.005 \\
\hline Diarrhea & $9(5.4)$ & $108(23.9)$ & $0.18(0.08-0.37)$ & $<0.001$ \\
\hline Anorexia & $39(23.2)$ & $189(41.8)$ & $0.42(0.27-0.64)$ & $<0.001$ \\
\hline Fatigue & $72(42.9)$ & $236(52.2)$ & $0.69(0.47-0.99)$ & 0.040 \\
\hline Neurological signs $^{\dagger}$ & $4(2.4)$ & $39(8.6)$ & $0.26(0.07-0.73)$ & 0.006 \\
\hline
\end{tabular}

*Food intolerance: repeated vomiting

${ }^{\dagger}$ Neurological signs: collapse, confusion, and encephalitis 
Table 2. Comparison of the biological variables in the univariate analysis between CHIKV and DENV groups

Tableau 2. Comparaison en analyse univariée des variables biologiques entre les groupes CHIKV et DENV

\begin{tabular}{|c|c|c|c|c|}
\hline Variables & $\begin{array}{c}\text { CHIKV } \\
\text { no. positive } \\
\text { / no. tested } \\
(\%)\end{array}$ & $\begin{array}{c}\text { DENV } \\
\text { no. positive } \\
\text { / no. tested } \\
(\%)\end{array}$ & OR $(95 \% \mathrm{CI})$ & $p$ \\
\hline Platelet count $<150 \mathrm{G} / 1$ & $18 / 153(11.8)$ & $200 / 445(44.9)$ & $\begin{array}{c}0.16(0.09- \\
0.28)\end{array}$ & $<0.001$ \\
\hline $\begin{array}{l}\text { Neutrophil count }<1,500 \\
/ \mathrm{mm}^{3}\end{array}$ & $10 / 152(6.6)$ & $86 / 444(19.4)$ & $\begin{array}{c}0.29(0.13- \\
0.59)\end{array}$ & $<0.001$ \\
\hline $\begin{array}{l}\text { Lymphocyte count } \\
<500 / \mathrm{mm}^{3}\end{array}$ & $20 / 152(13.1)$ & $138 / 440(31.4)$ & $\begin{array}{c}0.33(0.19- \\
0.56)\end{array}$ & $<0.001$ \\
\hline $\mathrm{CRP}^{*}>30 \mathrm{mg} / \mathrm{l}$ & $43 / 148(29.1)$ & $72 / 432(16.7)$ & $\begin{array}{c}2.05(1.29- \\
3.23)\end{array}$ & 0.001 \\
\hline $\mathrm{AST}^{* *}>2 \mathrm{~N} \dagger$ & $12 / 109(11.0)$ & $91 / 385(23.6)$ & $0.40(0.19-0.77)$ & 0.004 \\
\hline $\mathrm{ALT}^{* *}>2 \mathrm{~N} \dagger$ & $10 / 126(7.9)$ & $85 / 421(20.2)$ & $0.34(0.15-0.69)$ & 0.001 \\
\hline Creatinine $>115 \mu \mathrm{mol} / \mathrm{l}$ & $13 / 144(9.0)$ & $23 / 437(5.3)$ & $1.78(0.81-3.80)$ & 0.10 \\
\hline
\end{tabular}

$*$ C-reactive protein, ${ }^{\star *}$ aspartate transaminase (AST) and alanine transaminase (ALT)

$\dagger 2$-fold increase as compared with baseline 
Table 3. Logistic regression of clinical variables and $\beta$ coefficients in the multivariate analysis (Bootstrap x 3500)

Tableau 3. Analyse multivariée en régression logistique des variables cliniques avec $\beta$ coefficients (Bootstrap x 3500)

\begin{tabular}{lcccc}
\hline \multirow{2}{*}{ Variables } & Univariate analysis & \multicolumn{2}{c}{ Multivariate analysis with bootstrap procedure } \\
\cline { 3 - 5 } & OR (95\% CI) & $\boldsymbol{\beta}$ coefficients & OR (95\% CI) & $\begin{array}{c}\text { Predictive } \\
\text { score }\end{array}$ \\
\hline Headache & $0.30(0.20-0.45)$ & -0.86 & $0.42(0.20-0.92)$ & -1 \\
Joint pain & $66.4(34.4-136.8)$ & 4.7 & $106.8(38.5-$ & +5 \\
Muscle pain & $0.39(0.46-0.70)$ & -2.1 & $0.13(0.04-0.37)$ & -2 \\
Back pain & $3.08(2.08-4.55)$ & 0.74 & $2.09(1.01-4.31)$ & +1 \\
Nausea and/or & $0.27(0.18-0.41)$ & -1.2 & $0.31(0.16-0.60)$ & -1 \\
vomiting & & & & -2 \\
Diarrhea & $0.18(0.08-0.37)$ & -1.5 & $0.21(0.07-0.63)$ & -2 \\
Hemorrhagic & $0.03(0.004-0.13)$ & -3.4 & $0.04(0.01-0.13)$ & -3 \\
signs & & & & \\
\hline
\end{tabular}


Table 4. Clinical score predictive of dengue virus infection vs. chikungunya.

Tableau 4. Score clinique prédictif d'une infection par le virus de la dengue vs. chikungunya.

\begin{tabular}{lc}
\hline \multicolumn{1}{c}{ SCORE } \\
\hline Headache & -1 \\
Joint pain & +5 \\
Muscle pain & -2 \\
Back pain & +1 \\
Nausea and/or vomiting & -1 \\
Diarrhea & -2 \\
Hemorrhagic sign & -3 \\
\hline -9 to +2: DENV infection & \\
+3 to +6: CHIKV infection & \\
If arthritis: CHIKV infection & \\
\hline
\end{tabular}

